\title{
Effect of ultrasonic instrumentation on the bond strength of crowns cemented with zinc phosphate cement to natural teeth. An in vitro study
}

\begin{abstract}
Antonio Braulino de Melo Filho(a) Matsuyoshi Mori(b)

Maria Aparecida Neves Jardini(c) Karine Tenório Landimid

Ana Cristina de Oliveira Solis ${ }^{(e)}$
\end{abstract}

(a) Professor, Discipline of Restorative Dentistry; (c) Professor, Discipline of Periodontics; (d) Clinical Instructor, Discipline of Restorative Dentistry - School of Dentistry of São José dos Campos, São Paulo State University (UNESP), São José dos Campos, SP, Brazil.

(b) Professor, Department of Prosthodontics, School of Dentistry, University of São Paulo, São Paulo, SP, Brazil.

(e) Professor, Discipline of Periodontics, School of Dentistry, Vale do Paraíba University, São José dos Campos, SP, Brazil.

Corresponding author:

Antonio Braulino de Melo Filho

Av. Adhemar de Barros, 283/701

Vila Adyana

São José dos Campos, SP, Brazil

CEP: 12245-010

E-mail: braulino@directnet.com.br

Received for publication on Nov 01, 2006

Accepted for publication on Aug 10, 2007

\begin{abstract}
Several studies have reported the benefits of sonic and/or ultrasonic instrumentation for root debridement, with most of them focusing on changes in periodontal clinical parameters. The present study investigated possible alterations in the tensile bond strength of crowns cemented with zinc phosphate cement to natural teeth after ultrasonic instrumentation. Forty recently extracted intact human third molars were selected, cleaned and stored in physiologic serum at $4^{\circ} \mathrm{C}$. They received standard preparations, at a $16^{\circ}$ convergence angle, and AgPd alloy crowns. The crowns were cemented with zinc phosphate cement and then divided into four groups of 10 teeth each. Each group was then subdivided into two subgroups, with one of the subgroups being submitted to 5,000 thermal cycles ranging from $55 \pm 2$ to $5 \pm 2{ }^{\circ} \mathrm{C}$, while the other was not. Each group was submitted to ultrasonic instrumentation for different periods of time: group 1 - $0 \mathrm{~min}$ (control), group 2 - $5 \mathrm{~min}$, group 3 - $10 \mathrm{~min}$, and group 4 - $15 \mathrm{~min}$. Tensile bond strength tests were performed with an Instron testing machine (model 4310). Statistical analysis was performed using ANOVA and Tukey's test at the 5\% level of significance. A significant reduction in the tensile bond strength of crowns cemented with zinc phosphate and submitted to thermal cycles was observed at $15 \min (196.75 \mathrm{~N}$ versus $0 \mathrm{~min}=452.01 \mathrm{~N}, 5 \mathrm{~min}=444.23 \mathrm{~N}$ and 10 $\min =470.85 \mathrm{~N}$ ). Thermal cycling and ultrasonic instrumentation for 15 min caused a significant reduction in tensile bond strength $(\mathrm{p}<.05)$.
\end{abstract}

Descriptors: Zinc phosphate cement; Tensile strength; Tooth crown; Ultrasonic therapy. 


\section{Introduction}

Great technical advancement in ultrasonic apparatuses over the last few years has permitted their increased use and dissemination among professionals of various specialties. This technological evolution was possible because of the piezoelectric properties of some crystals or metals. ${ }^{1}$ Current devices develop less heat and, consequently, the possible discomfort caused by instrumentation of the root surface is also lower. Various investigators have reported benefits of sonic and/or ultrasonic instruments in root instrumentation, emphasizing the improvement of periodontal clinical parameters. ${ }^{1-3}$ A systematic review regarding the efficacy of machine-driven and manual subgingival debridement also concluded that less time may be required for periodontal treatment when ultrasonic instead of manual instrumentation is used. ${ }^{4}$

However, clinical sequelae such as fractures of ceramic prosthetic restorations and percolation of composite resin restorations have been reported with the use of ultrasound. ${ }^{5,6}$ This occurs because in patients with fixed intrasulcular dentures the active tip of the ultrasound apparatus may come in contact with the border of the denture, altering the bond strength of the cementing agent.

Zinc phosphate cement has been used in clinical practice. ${ }^{7,8}$ The possibility that ultrasonic instrumentation may cause fragility of the zinc phosphate cement has been widely accepted for intraradicular retainers $^{9-11}$ but little is known about its action on crowns and fixed partial dentures. ${ }^{12,13}$

Thus, the objective of the present study was to determine the in vitro effect of ultrasonic instrumentation on the bond strength of crowns cemented with a zinc phosphate agent to teeth receiving standardized preparations compared to that observed on teeth not submitted to instrumentation.

\section{Material and Methods}

Forty recently extracted intact human third molars were selected, in such a way that the distance between opposite sides at the cementoenamel junction would be greater than $8.5 \mathrm{~mm}$. They were cleaned and stored in physiologic serum at $4{ }^{\circ} \mathrm{C}$. The preparations were standardized, with their op- posite walls presenting a convergence angle of 16 degrees. Crowns were manufactured with AgPd alloy (Palliag M, Degussa Dental Ltda., Guarulhos, SP, Brazil). Cementation with zinc phosphate cement (SS White, Artigos Dentários Ltda., Rio de Janeiro, RJ, Brazil) was performed according to the manufacturer's instructions. The 40 cemented teeth were divided into four groups of 10 teeth each. Each group was subdivided into two subgroups of 5 teeth each, with one subgroup being submitted to thermal cycling $(5,000$ thermal cycles ranging from $55 \pm 2$ to $5 \pm 2^{\circ} \mathrm{C}$ ) and the other not. After this procedure, the specimens were submitted to ultrasonic instrumentation for different periods of time: group 1 (control) was not submitted to ultrasonic instrumentation, group 2 was submitted to ultrasonic instrumentation for $5 \mathrm{~min}$, group 3, for $10 \mathrm{~min}$, and group 4, for $15 \mathrm{~min}$ (Table 1 ).

Ultrasonic instrumentation was performed at the cervical limit of the crowns with an ultrasound apparatus (Profi III Bios Dabi Atlante S.A., Ribeirão Preto, SP, Brazil) set to work at $60 \%$ of maximum power.

Next, the specimens were submitted to tensile bond strength tests using a universal testing machine (Instron model 4301, Caton, MA, USA) with a load capacity of $5 \mathrm{kN}$ at a speed of $0.5 \mathrm{~mm} / \mathrm{s}$.

\section{Statistical analysis}

The data were stored in Microsoft Excel for Windows and analyzed using Statistix for Windows (version 7.0, 2000, Analytical Software, Inc., Tallahassee, FL, USA) and Statistica for Windows (version 5.5, 2000, StatSoft Inc., Tulsa, OK, USA) programs. The tensile bond strength results were analyzed by two-way analysis of variance (ANOVA). The level

Table 1 - Groups $(n=5)$ and periods of time of ultrasonic instrumentation.

\begin{tabular}{c|c|c}
\hline $\begin{array}{c}\text { Time of ultrasonic } \\
\text { instrumentation }\end{array}$ & $\begin{array}{c}\text { Without cycling } \\
(\mathrm{n}=20)\end{array}$ & $\begin{array}{c}\text { With cycling } \\
(\mathrm{n}=20)\end{array}$ \\
\hline 0 minutes & 5 & 5 \\
\hline 5 minutes & 5 & 5 \\
\hline 10 minutes & 5 & 5 \\
\hline 15 minutes & 5 & 5 \\
\hline
\end{tabular}


of significance adopted for rejection of the hypothesis of equality between the effects produced by the factors as well as the interaction effects of these factors was set at $5 \%$. In the case of rejection of these hypotheses, the Tukey test was used at the $5 \%$ level to detect at which level this difference occurred.

\section{Results}

Means of tensile force and the results of the descriptive analysis are shown in Tables 2 and 3, respectively.

Statistical significance of differences among groups was tested by two-way ANOVA (Table 2).

Post hoc multiple comparisons were performed by the Tukey test (Table 3)

\section{Discussion}

Ultrasonic instruments are extensively applied in dentistry for the removal of dental calculus ${ }^{1,4}$ and intraradicular retainers. ${ }^{10,14}$ Other investigators also indicated its use for the removal of crowns. ${ }^{12,15}$ Howev-

Table 2 - Two-way analysis of variance (ANOVA).

\begin{tabular}{l|c|c|c|c|c}
\hline Variable & $\begin{array}{c}\text { Degrees of } \\
\text { freedom }\end{array}$ & $\begin{array}{c}\text { Sum of } \\
\text { squares }\end{array}$ & $\begin{array}{c}\text { Mean of } \\
\text { squares }\end{array}$ & $F$ & Probability \\
\hline Time & 3 & 181974 & 60658.0 & 8.65 & 0.0002 \\
\hline Cycling & 1 & 317793 & 317793 & 45.31 & 0.0000 \\
\hline Interaction & 3 & 83751.4 & 27917.1 & 3.98 & 0.0162 \\
\hline Residual & 32 & 224430 & 7013.43 & & \\
\hline Total & 39 & 807948 & & & \\
\hline
\end{tabular}

Table 3 - Means $(N)$ and standard deviations of tensile bond strength.

\begin{tabular}{l|c|c|c}
\hline Cycling & Time (minutes) & Mean \pm SD & Tukey analysis \\
\hline \multirow{4}{*}{$\begin{array}{l}\text { Without } \\
\text { (N) }\end{array}$} & 10 & $599.18 \pm 119.74$ & $\mathrm{~A}$ \\
\cline { 2 - 4 } & 5 & $582.93 \pm 83.62$ & $\mathrm{~A}$ \\
\cline { 2 - 4 } & 15 & $562.24 \pm 46.64$ & $\mathrm{~A}$ \\
\hline \multirow{4}{*}{$\begin{array}{l}\text { With } \\
\text { (N) }\end{array}$} & 10 & $470.85 \pm 50.08$ & $\mathrm{~A}$ \\
\cline { 2 - 4 } & 0 & $452.01 \pm 40.89$ & $\mathrm{~A}$ \\
\cline { 2 - 4 } & 5 & $444.23 \pm 35.16$ & $\mathrm{~A}$ \\
\hline
\end{tabular}

Means with different letters were significantly different at $P<.05$. er, the findings of these studies are contradictory, and this discrepancy might be explained by factors such as conicity of the preparation, time of instrumentation, type of cementing agent and thermal cycling. ${ }^{13,15}$

In the present study, a $16^{\circ}$ conicity was prepared since it provides adequate tensile bond strength for crowns cemented with zinc phosphate cement and it is closest to the convergence angle obtained in clinical practice. ${ }^{16,17}$

The time of instrumentation seems to be decisive in the reduction of the tensile bond strength of crowns cemented with zinc phosphate cement. ${ }^{12}$ Bond strength is provided by mechanical interlocking between cement and crown and between cement and tooth due to the fact that, no matter how smooth a surface seems, it contains irregularities at the microscopic level.

In ultrasonic instrumentation, vibration causes fracture of the cement that fills irregularities in the crown and dental surface, with cement fracture reducing bond strength. ${ }^{12,18}$ A significant reduction in tensile bond strength was observed in studies employing longer ultrasonic instrumentation times, probably because of greater cement fracture.

In the present study, a duration of ultrasonic instrumentation shorter than $15 \mathrm{~min}$ did not reduce tensile strength, while at $15 \mathrm{~min}$ the reduction was significant. Similar results have been reported by Matsumura et al. ${ }^{18}$ (1996) although shorter instrumentation periods, in absolute terms, were employed by the authors because the specimens were smaller.

A reduction in tensile bond strength has also been reported for specimens submitted to thermal cycling. ${ }^{19,20}$ However, the number of cycles used seems to be a determining variable. ${ }^{19,21}$ Thermal cycling exerts the same effect on cement, i.e., the difference in the coefficient of linear thermal expansion between tooth, cement and metal causes distinct movements of these substances, which in turn lead to fracture of the interlocking materials and, consequently, a reduction in tensile bond strength. Brown et al. ${ }^{19}$ (1972) showed that 3,650 cycles corresponded to one year of aging. In the present study, 5,000 cycles were applied which correspond to an approximate use of one year and six months.

Ultrasonic instrumentation and thermal cycling ex- 
ert an analogous effect on cements. Therefore, in the present study the combined effect of these two procedures was evaluated. Our results showed that under the present experimental conditions the combination of 5,000 cycles and 15 min of ultrasonic instrumentation caused a drastic reduction in the tensile strength of crowns cemented with zinc phosphate cement, while periods shorter than 15 min or even the absence of ultrasonic instrumentation did not reduce tensile strength, probably because of the lack of fracture of the cement that is in contact with the tooth or crown.

The present findings suggest that ultrasonic instrumentation should be performed with moderation, especially in the case of teeth with alloy crowns. Although in most cases a long period of ultrasonic instrumentation cannot be avoided during active periodontal treatment, in a single tooth the sum of periods of instrumentation during supportive periodontal treatment can be decisive and can culminate in a reduction of the tensile bond strength of the crown. As a result, just a few years of supportive periodontal treatment would be sufficient to damage the cementing agent.

This problem might be more evident and is more likely to occur at sites with little clinical attachment loss. At these sites, the end of the crowns is close to the region of ultrasonic instrumentation, in contrast to sites with extensive clinical attachment loss where the cervical end of the crowns is more distant from the instrumentation area. As a consequence, the active tip of the scaler will eventually touch the border of the crown.

Further studies varying the cervical end of the preparation, alloys, cements, crown-coating material, and mechanical cycling should be performed

\section{References}

1. Drisko CL, Cochran DL, Blieden T, Bouwsma OJ, Cohen RE, Damoulis $\mathrm{P}$ et al. Research, Science and Therapy Committee of the American Academy of Periodontology. Position paper: sonic and ultrasonic scalers in periodontics. J Periodontol. 2000;71(11):1792-801.

2. Cobb CM. Clinical significance of non-surgical periodontal therapy: an evidence-based perspective of scaling and root planing. J Clin Periodontol. 2002; 29 Suppl 2:6-16. to determine their interrelationship with ultrasonic instrumentation.

In addition, clinical studies should be conducted to verify whether the probability of crowns becoming loose is indeed higher in patients with zinc phosphate-cemented crowns whose teeth are frequently instrumented with ultrasonic instruments. If this is true, new conducts should probably be established for the use of ultrasonic instruments, especially in the case of teeth with cemented crowns with healthy clinical attachment levels.

It should be pointed out that an ideal $16^{\circ} \mathrm{co}-$ nicity of the preparation - which would render adequate tensile bond strength - may not be achieved in clinical practice. Therefore, the time of instrumentation necessary to cause fracture of the cementing agent may vary and can be even shorter, a fact indicating the need for further investigation of this event among professionals who routinely use ultrasound.

\section{Conclusions}

We conclude that the variables ultrasonic instrumentation and thermal cycling influence the tensile bond strength of crowns cemented with zinc phosphate cement. Thermal cycling and ultrasonic instrumentation for 15 min caused a significant reduction in tensile bond strength.

\section{Acknowledgments}

This study was supported by grants from the Fundação da Universidade Estadual Paulista (FUNDUNESP: 587/01). The authors are grateful to Ivan Balducci for his assistance with the statistical analysis.

3. Obeid PR, D’Hoore W, Bercy P. Comparative clinical responses related to the use of various periodontal instrumentation. J Clin Periodontol. 2004;31(3):193-9.

4. Tunkel J, Heinecke A, Flemmig TF. A systematic review of efficacy of machine-driven and manual subgingival debridement in the treatment of chronic periodontitis. J Clin Periodontol. 2002; 29 Suppl 3:72-81; discussion 90-1. 
5. Gorfil C, Nordenberg D, Liberman R, Ben-Amar A. The effect of ultrasonic cleaning and air polishing on the marginal integrity of radicular amalgam and composite resin restorations. An in vitro study. J Clin Periodontol. 1989;16(3):137-9.

6. Lee SY, Lai YL, Morgano SM. Effects of ultrasonic scaling and periodontal curettage on surface roughness of porcelain. J Prosthet Dent. 1995;73(3):227-32.

7. Felton DA, Kanoy BE, White JT. Recementation of dental casting with zinc phosphate cement: Effect on cement bond strength. J Prosthet Dent. 1984;58(5):579-83.

8. Marker VA, Miller AW, Miller BH, Swepston JH. Factors affecting the retention and fit of gold castings. J Prosthet Dent. 1987;57(4):425-30.

9. Berbert A, Filho MT, Ueno AH, Bramante CM, Ishikiriama A. The influence of ultrasound in removing intraradicular posts. Int Endod J. 1995;28(2):100-2.

10. Buoncristiani J, Seto BG, Caputo AA. Evaluation of ultrasonic and sonic instruments for intraradicular post removal. J Endod. 1994;20(10):486-9.

11. Yoshida T, Gomyo S, Itoh T, Shibata T, Sekine I. An experimental study of the removal of cemented dowel-retained cast cores by ultrasonic vibration. J Endod. 1997;23(4):239-41.

12. McQuade MJ, Huget EF, de Simon LB, Levin MP. Effect of ultrasonic instrumentation on the retention of simulated cast crowns. J Prosthet Dent. 1978;39(6):640-2.
13. Olin PS. Effect of prolonged ultrasonic instrumentation on the retention of cemented cast crowns. J Prosthet Dent. 1990;64(5):563-5.

14. Johnson WT, Leary JM, Boyer DB. Effect of ultrasonic vibration on post removal in extracted human premolar teeth. J Endod. 1996;22(9):487-8.

15. Badawi BA, Mokhtar AH, Sherif AH, Shehata MT. Effect of application of ultrasonic vibration on the cement bond strength of cemented cast crowns. Egypt Dent J. 1994;40(3):833-8.

16. Dodge WW, Weed RM, Baez RJ. The effect of convergence angle on retention and resistance form. Quintessence Int. 1985;16(3):191-4.

17. Weed RM. Determining adequate crown convergence. Tex Dent J. 1980;98(5):14-6.

18. Matsumura H, Salonga JP, Taira Y, Atsuta M. Effect of ultrasonic instrumentation on bond strength of three dental cements bonded to nickel-chromium alloy. J Prosthet Dent. 1996;75(3):309-13.

19. Brown WS, Jacobs HR, Thompson RE. Thermal fatigue in teeth. J Dent Res. 1972;51(2):461-7.

20. Hung CM, Weiner S, Dastane A. Effect of thermocycling and occlusal force on the margins of provisional acrylic resin crowns. J Prosthet Dent. 1993;69(6):573-7.

21. Tjan AH, Miller GD, Whang SB, Sarkissian R. The effect of thermal stress on the marginal seal of cast gold full crowns. J Am Dent Assoc. 1980;100(1):48-51. 